Article

\title{
Short Term Electric Production Technology Switching Under Carbon Cap and Trade
}

\section{Timothy Considine ${ }^{1, *}$ and Donald F. Larson ${ }^{2}$}

1 Department of Economics and Finance, University of Wyoming, 1000 University Ave, Laramie, WY 82072, USA

2 The Development Research Group, World Bank, 1818 H St., N.W., Washington, DC 20433, USA; E-Mail: dlarson@worldbank.org

* Author to whom correspondence should be addressed; E-Mail: tconsidi@uwyo.edu; Tel.: +1-307-766-2543; Fax: +1-307-766-5090.

Received: 1 September 2012; in revised form: 24 September 2012 / Accepted: 10 October 2012 / Published: 23 October 2012

\begin{abstract}
This study examines fuel switching in electricity production following the introduction of the European Union's Emissions Trading System (EU ETS) for greenhouse gas emissions. A short-run restricted cost equation is estimated with carbon permits, high-carbon fuels, and low carbon fuels as variable inputs. Shadow values and substitution elasticities for carbon-free energy resources from nuclear, hydroelectric and renewable sources are imputed from the cost equation. The empirical analysis examines 12 European countries using monthly data on fuel use, prices, and electricity generation during the first phase of the European Emissions Trading System. Despite low emission permit prices, this study finds statistically significant substitution between fossil fuels and carbon free sources of energy for electric power production. Significant substitution between fossil fuels and nuclear energy also was found. Still, while 18 of the 20 substitution elasticities are statistically significant, they are all less than unity, consistent with limited substitution. Overall, these results suggest that prices for carbon emission permits relative to prices for carbon and carbon free sources of energy do matter but that electric power producers have limited operational flexibility in the short-run to satisfy greenhouse gas emission limits.
\end{abstract}

Keywords: electricity; EU ETS; technology; switching; carbon; trading 


\section{Introduction}

The European Union (EU) has pioneered the development of a carbon dioxide $\left(\mathrm{CO}_{2}\right)$ emissions trading program, known as the Emissions Trading System (ETS). Operating since early 2005, this program mandates an overall limit or cap on carbon emissions and requires a permit or allowance for the operation of nearly all stationary sources of $\mathrm{CO}_{2}$ emissions that originate from large industrial facilities and electric power generating plants. By allocating a supply of permits and creating a demand for $\mathrm{CO}_{2}$, the EU ETS has created a market for disposing carbon dioxide emissions in the atmosphere and as a consequence, a mechanism for pricing $\mathrm{CO}_{2}$ emissions.

Under the legal and regulatory framework established by the EU ETS, producers of carbon intensive goods and services covered by the program must consider emissions in their production decisions, weighing the costs of purchasing permits with the benefits of selling excess permits created by using less carbon-intensive inputs or by investing in less carbon-intensive technologies. The objective of this study is to understand the nature of relationships among permit use and usage of electricity generation assets under carbon cap and trade. In pursuit of this goal, the study specifies and estimates an econometric model of electricity technology switching or substitution in Europe.

According to Ellerman et al. [1] the electric power sector accounts for $60 \%$ of carbon emissions in the EU and constitutes $90 \%$ of the potential demand and $50 \%$ of total supply of carbon allowances. Electric power producers have a variety of options to reduce their carbon emissions. In the short run, they can shift among a fixed set of generation capacities, moving from high carbon to lower carbon fuel sources or raising their utilization of carbon-free capacity. Longer term, electricity producers can invest in new capacity, such as advanced nuclear plants, coal with carbon capture and sequestration systems, or renewable energy resources, including wind, solar, biomass, and geothermal capacity.

Decisions to invest in new capacity will be influenced in part by the ability of the existing fleet of generating plants to adapt to carbon emission constraints. As carbon emission limits become more stringent, the ability to adjust becomes more difficult and the marginal cost of electricity rises, inducing new investment in carbon-free sources of electricity. How readily electricity producers can switch fuels in response to price signals remains a key question in estimating the costs of carbon emission controls. Determining the extent of these price-induced substitutions within a short-run context is a key first step in assessing the long-term adjustments necessary to significantly reduced greenhouse gas emissions.

The empirical challenge is to model the range of choices available to electric power producers in the short run as they shift their utilization of existing capacity. For example, producers can shift production from high carbon capacity, such as coal and oil, to less carbon intensive natural gas, or carbon free capacity, such as nuclear, hydroelectric, or renewable energy sources of generation. While estimating short-run substitution between fossil fuels with observable prices is feasible, estimation of substitution possibilities for carbon free sources of generation is problematic because factor prices for these resources are not observed. Halvorsen and Smith [2], however, show a way around this problem. In their study of internally produced ore inputs in metal mining, they use a restricted cost equation in which un-priced inputs are treated as quasi-fixed factors, even though they can vary along with other inputs. As a practical matter, chief distinction is that quasi-fixed inputs in the model do not have observable prices, so levels are used in the cost equation instead, from which shadow values can be 
imputed. This specification is advantageous because delivered prices for electricity from renewable electric power generation technologies are difficult to impute under subsidies and renewable portfolio standards. Moreover, under this specification the convexity conditions provide a basis for deriving the elasticities of demand and substitution. Accordingly, this study utilizes a restricted cost equation in which electricity producers minimize the variable costs of production including inputs of coal, natural gas, petroleum, and carbon allowances, all of which have observable prices, subject to inputs of carbon-free energy resources, including nuclear, hydroelectric, and renewable resources.

Including all possible sources of generation in a model of input substitution in electric power production is unique. Most empirical studies limit substitution possibilities to a smaller set of fossil fuel inputs used in steam electric power generation, following an approach used in pioneering studies by Nerlove [3], Christensen and Green [4], and Atkinson and Halvorsen [5], among others, as surveyed by Cowing and Smith [6]. However, as Hobbs [7] notes, electric power producers often consider these fossil fuel use decisions together with decisions about the use of non-fossil fuel capacity, such as nuclear, hydroelectric, and renewable energy facilities.

At its most basic level, electric power generation involves converting one form of energy to another. Coal is combusted to generate steam that then drives turbines, which generate electricity. Wind energy powers turbines to generate electricity just as steam does. Nuclear fuels and solar thermal technologies are used in precisely the same way. Electric power generators also convert the chemical energy in natural gas or petroleum using the same principles. While seemingly disparate, these technologies share a common feature, the conversion of one form of energy to electric energy. The energy units consumed by these generators are proportional to their electric power generation. Viewed from this perspective, the restricted cost equation approach adopted in this paper provides a framework for evaluating short-tern technology switching or substitution in electric power generation.

The prime objective of this paper, however, is to classify these fuel sources to estimate how the utilization of these inputs adjusts to changing relative prices for carbon emission permits. Clearly, electricity producers are using a multitude of electrical generation sources to achieve their objectives. Our approach is a reasonable first step at estimating this broad array of switching possibilities. Accordingly, this study develops a framework for estimating the full range of technology switching possibilities that electricity producers face as they minimize their costs in the short-run.

Previous studies have already noted evidence of fuel-switching from coal to natural gas when EU ETS allowance prices rise (De Leyva and Lekander [8]; Delarue and D'haeseleer [9]). However, not all types of power generation are as easily scaled or brought on-line. Fixed costs dominate hydro and nuclear facilities lessening the direct influence of carbon prices. The same is true energy generated by wind turbines or solar panels, where the vagaries of weather also intervene. All of this provides justification for their exclusion from earlier studies about the consequences of allowance prices. Still, the lead-times needed to develop wind and solar sourced power are not lengthy and renewables free more allowances than switching from coal to natural gas, thereby spurring new investments and providing incentives to keep existing capacity on-line (Bird et al. [10]; Hoffmann [11]; Butler and Neuhoff [12]). And, as described later in Section 5, renewable energy capacity did increase significantly during the study period. Moreover, operators have some leeway in when hydro or nuclear plants are taken off-line, either for repair or in response to power prices. For example, in his study of the German nuclear power subsector, Nicolosi [13] cites technical documents suggesting considerable 
flexibility in the German fleet of nuclear plants, and provides evidence that the subsector responds to prices, albeit inelastically. With this in mind, we do not, as in previous studies, impose form restrictions that imply that allowance prices have no impact on power generated from these sources, but instead use an adequately flexible form to settle the matter empirically.

The model is estimated using a panel of monthly time series observations from January 2005 through March 2008 for a cross section of twelve European countries. The possible correlation between changes in maintenance schedules, temperature, and other factors with changes in prices is addressed through the use of instrumental variables in the estimation of the model. Lagged output and lagged levels of the inputs including nuclear, hydroelectricity, and renewable energy are included as instruments. Changes in maintenance and other factors affecting the level and mix of inputs are accounted for in the model. The observed levels of generation by type reflect exogenous events, such as droughts, wind seasonality, or nuclear-plant-shutdowns. By definition, the demand for electricity is equal to output plus net imports. Electricity demand shifts with changes prices, income or gross domestic product, and temperature, among other factors. Though not reported here, we also estimated the model with demand equations and with markup pricing rules and the estimated elasticities of substitution are very similar to results from our preferred model presented below. The relatively large number of observations and considerable variation in the data allows the estimation of variable returns to scale. The study provides explicit measures of the degree of carbon abatement, such as carbon emissions per unit of electricity output, under the EU ETS and, most importantly, explains how this abatement was achieved.

Specifically, the degree of electricity technology switching induced by carbon pricing and relative fuel prices is estimated. This empirical assessment of carbon substitution possibilities sheds light on whether carbon pricing significantly increases the demand for less carbon intensive fuels, such as natural gas, at the expense of carbon intensive fuels, such as coal. These substitution possibilities ultimately determine whether the demand for carbon emission abatement is price inelastic, which would imply significant adjustment costs to a low carbon society, or whether carbon emission abatement demand is elastic, facilitating a less costly path to achieving significant reductions in carbon emissions.

The next section provides some additional background on the European program. Section 3 presents the economic framework, discussing the theoretical underpinnings for the empirical model. The parametric specification of the econometric model is then presented in the fourth section along with a discussion of the estimation techniques. Section 5 provides an overview of the data sample, including descriptive statistics by country on electricity generation by type, net imports, total generation, and the composition of so-called combustible fuels, including natural gas, coal, and petroleum. Trends in the carbon intensity of electricity and in fuel shares in the sample are also identified and discussed. The sixth section of the paper discusses the econometric results and the implications for assessing short-term technology switching under carbon cap and trade. The final section summarizes the major findings and discusses the policy implications of the results.

\section{EU Emissions Trading Scheme}

In 2003, the European Council and Parliament approved legislation that eventually launched the EU ETS in 2005. The ETS is a cap-and-trade program that limits carbon dioxide emissions from more than 
10,000 installations located in the thirty member states of the European Economic Area. Currently, the sectors covered by the program include energy activities (e.g., electric-power generation greater than $20 \mathrm{MW}$ ), ferrous metals industries (iron and steel), mineral industries (cement, glass, ceramics, oil refineries, etc.), and pulp and paper industries. The program is considered a key element in the European Union's plan to meet its commitment under the Kyoto Protocol to reduce greenhouse gas emissions by eight percent compared to 1990 levels by the end of 2012. For more information on the EU ETS see Watanabe and Robinson [14], Convery and Redmond [15] and Europa [16].

Our study period, January 2005 to March 2008, covers two phases of the program. Practical implementation of the program meant establishing an extensive system of procedures for allocating allowances, for monitoring how they are used, and for matching allowances with measured emissions. For this reason, Phase 1 (2005-2007) of the cap-and-trade program was intended in part as an opportunity to work out operational difficulties in advance of Phase 2 of the program, which corresponds to the first round of commitments (2008-2012) under the Kyoto Protocol.

As discussed, under the program regulated installations are issued permits, called EU allowances (EUAs), equivalent to one ton of emitted carbon dioxide. The allocations are made in accordance with National Allocation Plan (NAP), drawn-up by individual Member States. At the end of each year, regulated installations must surrender allowances equivalent to their emissions. Surplus and short-falls can be matched through sales and purchases. The allowances are tracked in national registries that were linked to form a system-wide registry during the program's second phase.

Though restrictions apply, the system is open to other tradable units established under the Kyoto Protocol, including Certified Emission Reductions (CERs) from developing countries. This is significant, since it potentially links the two types of carbon offsets into a large and liquid market, making the findings of this study relevant for developing countries. Legislation known as the "Linking Directive" lays out the relationship between EUAs and the Kyoto-system tradable units. For an early assessment of the ETS, see the volume edited by Ellerman, Buchner and Carraro [1]. For more on carbon markets in general, see Larson et al. [17].

\section{The Economic Model}

The output of electricity depends upon inputs of labor and maintenance, capital service flows from generating equipment and structures, and primary fuels. In addition, under the EU ETS producers of electricity are required to obtain pollution permit allowances to offset their emissions of carbon dioxide. Hence, the disposal of the carbon dioxide by-products of electricity generation now becomes a factor of production. These observations imply the following production equation for electricity:

$$
Y_{t}=f\left(K_{t}, L_{t}, E_{t}, C_{t}\right)
$$

where $Y_{t}$ is output of electricity in period $\mathrm{t}, K_{t}$ is capital service flows, $L_{t}$ is salaried and hourly worker services, maintenance, and non-fuel supplies, $E_{t}$ is an aggregate of energy inputs, and $C_{t}$ is carbon emissions.

Assuming capital and labor are fixed in the short run, under duality theory the following total cost equation exists: 


$$
T C_{t}=C\left(w_{e t}, w_{c t} \mid K_{t}, L_{t}, Y_{t}\right)+\mu_{k t} K_{t}+\mu_{l t} L_{t}
$$

where $C$ is total variable cost, $w_{e t}$ and $w_{c t}$ are prices for energy and carbon respectively, and $\mu_{k t}$ and $\mu_{l t}$ are the user costs corresponding with stocks of labor and capital. Prices for carbon emission allowances represent the societal valuation of the impacts of carbon emissions on common property atmospheric resources implicit in the target level of allowable emissions and the corresponding allocation of permits. This approach is similar to the study conducted by Considine and Larson [18] of sulfur dioxide pollution allowances.

For the empirical analysis below, $K_{t}$ and $L_{t}$ are unobservable. Specifying an empirical model, therefore, requires assuming the existence of a weakly separable sub-aggregate of energy and carbon emissions within the variable cost equation. In particular, the weakly separable model implies that optimal mix of electricity technologies and carbon emissions are independent of substitution possibilities between labor and capital. The cost minimization problem, therefore, is to minimize energy and carbon emission allowance costs subject to output levels and fixed levels of capital and labor.

In the context of the model, there are three types of energy aggregates: (i) primary fossil fuels, including coal, petroleum, and natural gas; (ii) nuclear fuel and hydroelectric energy; and (iii) renewable energy resources, including wind, solar, and geothermal energy. As discussed, while market prices for primary fuels are observable, those for nuclear, hydroelectric, and renewable energy are not. To accommodate this fact, this study assumes the existence of a weakly separable sub-aggregate for primary energy and carbon emissions contingent upon levels of nuclear, hydroelectric, and renewable energy generation, levels of output and the state of technology. More specifically, this implies the following short-run restricted energy and emission allowance cost equation:

$$
G_{t}=G\left(w_{1 t}, w_{2 t}, w_{3 t} \mid N_{t}, R_{t}, Y_{t}, Z_{t}\right)
$$

where $Z_{t}$ is an index of technological change, $w_{1 t}$ is the price for carbon emission allowances; $w_{2 t}$ is the is the price for solid and liquids fuels, such as coal and fuel oil with relatively high carbon content; $w_{3 t}$ is price of natural gas with relatively low carbon content; $N_{t}$ is the consumption of carbon-free nuclear and hydroelectric energy; and $R_{t}$ is carbon-free renewable energy resource use.

An engineering perspective on this model can be attained by noting that the consumption of a primary fuel at a specific plant is equal to the heat rate, which is define as the amount of fuel consumed per unit of electricity, multiplied by the level of power generation from that facility. So from this perspective, the short-run restricted variable cost equation specified above in Equation (3) can be viewed as a model that selects the least cost mix of plant capacity operating in any time period. This model is analogous to least cost scheduling algorithms commonly employed by electricity companies and system operators.

\section{Econometric Model}

Unlike the Halverson and Smith study [2], which used a translog (TL) equation, the model presented below is based upon the Generalized Leontief (GL) restricted cost equation developed by Morrison [14]. Morrison also shows that the GL allows closed form solutions for equilibrium levels of quasi-fixed inputs, which facilitates computation of substitution elasticities and their standard errors. 
The Generalized Leontief (GL) equation developed by Morrison [19] is best suited for this particular problem because it is more likely to maintain cost minimizing curvature conditions under limited input substitution possibilities, which is a reasonable prior assumption for electric power generation, see Caves and Christensen [20]. Consistent with the econometric literature in inter-fuel substitution, our model provides a continuous approximation of what are stepwise cost equations for time units less than the monthly frequency used in this study. Another important reason for choosing the form is that the GL provides a closed-form solution for stocks of quasi-fixed factors, which facilitates computation of substitution elasticities. For this study, the GL takes the following form:

$$
\begin{aligned}
G_{t}= & Y_{t}\left\{\begin{array}{l}
\sum_{i=1}^{3} \sum_{j=1}^{3} \alpha_{i j}\left(w_{i t} w_{j t}\right)^{1 / 2}+\sum_{i=1}^{3} \delta_{y i} w_{i t} Y_{t}^{1 / 2}+\sum_{i=1}^{3} \delta_{z i} w_{i t} Z_{t}^{1 / 2} \\
+\sum_{i=1}^{3} w_{i t}\left(\gamma_{y y} Y_{t}+2 \gamma_{y z} Y_{t}^{1 / 2} Z_{t}^{1 / 2}+\gamma_{z z} Z_{t}\right)+\sum_{i=1}^{3} w_{i t} \varepsilon_{i t}
\end{array}\right\} \\
& +Y_{t}^{1 / 2}\left\{\begin{array}{l}
\sum_{i=1}^{3} \delta_{n i} w_{i t} N_{t}^{1 / 2}+\sum_{i=1}^{3} \delta_{r i} w_{i t} R_{t}^{1 / 2} \\
+\sum_{i=1}^{3} w_{i t}\left(\gamma_{y n} Y_{t}^{1 / 2} N_{t}^{1 / 2}+\gamma_{y r} Y_{t}^{1 / 2} R_{t}^{1 / 2}+\gamma_{z n} Z_{t}^{1 / 2} N_{t}^{1 / 2}+\gamma_{z r} Z_{t}^{1 / 2} R_{t}^{1 / 2}\right)
\end{array}\right\} \\
& +\sum_{i=1}^{3} w_{i t}\left(\gamma_{n n} N_{t}+2 \gamma_{n r} N_{t}^{1 / 2} R_{t}^{1 / 2}+\gamma_{r r} R_{t}\right)+\sum_{i=1}^{3} \sum_{c=1}^{12} w_{i t} \delta_{c}^{i} D_{c t}+\varepsilon_{g t}
\end{aligned}
$$

where the $\alpha^{\prime} s, \delta^{\prime} s$ and $\gamma^{\prime} s$ are unknown parameters, the $\varepsilon_{i t}$, and $\varepsilon_{g t}$ are stochastic errors. Note the cost Equation (4) is dual to the production equation and includes prices for three variable inputs: high carbon fuel, $x_{1 t}$, low-carbon fuel, $x_{2 t}$, and carbon emissions, $x_{3 t}$. The last term in Equation (4) represents fixed country effects that capture factors unique to each country other than their levels of relative prices and the availability of nuclear, hydroelectric, and renewable energy and the level of power generation in each country. The restricted cost equation is symmetric and homogeneous of degree zero in prices. The asymmetric way that output and technological change enter the cost equation facilitates parametric testing of constant returns to scale. Corresponding the country-subscript $c$, the countries in order from one to twelve are Austria, Denmark, Finland, France, Germany, Greece, Netherlands, Portugal, Spain, Poland, Sweden, and UK. These countries are selected because they have complete observations for the sample period.

The input demand equations for high carbon fossil fuels (petroleum and coal), low carbon fuels (natural gas), and carbon are equal to the derivative of Equation (4) with respect to factor prices. These expressions are as follows:

$$
\begin{aligned}
X_{i t}= & \sum_{c=1}^{12} \delta_{c}^{i} D_{c t}+Y_{t}\left[\sum_{j=1}^{3} \alpha_{i j}\left(\frac{w_{j t}}{w_{i t}}\right)^{1 / 2}+\delta_{y i} Y_{t}^{1 / 2}+\delta_{z i} Z_{t}^{1 / 2}+\gamma_{y y} Y+2 \gamma_{y z} Y_{t}^{1 / 2} Z_{t}^{1 / 2}+\gamma_{z z} Z_{t}\right] \\
& +\delta_{n i}\left(Y_{t} N_{t}\right)^{1 / 2}+\delta_{r i}\left(Y_{t} R_{t}\right)^{1 / 2}+\gamma_{y n} Y_{t} N_{t}^{1 / 2}+\gamma_{y r} Y_{t} R_{t}^{1 / 2}+\gamma_{z n}\left(Y_{t} Z_{t} N_{t}\right)^{1 / 2}+\gamma_{z r}\left(Y_{t} Z_{t} R_{t}\right)^{1 / 2} \\
& +\gamma_{n n} N_{t}+2 \gamma_{n r}\left(N_{t} R_{t}\right)^{1 / 2}+\gamma_{r r} R_{t}+\varepsilon_{i t} \quad \forall i
\end{aligned}
$$

where $x_{i t}$ are levels of high and low carbon fuel consumption and carbon emissions. The variable input-output ratios are an equation of relative input prices conditional upon electricity production and 
the availability of hydroelectric, nuclear, and renewable energy resources. Note that further differentiating between base and peak load electricity would require arbitrarily designating generating facilities as base and peak load facilities when in fact many generators provide power during off and on-peak periods simultaneously. The full model includes the restricted variable cost Equation (4), and the three variable input demand functions given by Equation (5).

Since we do not have observable data on profits, a cost equation is estimated; however, by duality theory, the information from the cost equation reflects behavior consistent with profit maximization. For example, our model allows switching from coal to natural gas that will reduce carbon emissions and increase the marginal cost of electricity. As already discussed, we estimated two alternative models with a demand model and a price equation with and without markup pricing. Because there are no major changes in the substitution elasticities, we report only the results from our preferred model to conserve space.

Following the approach developed by Morrison [19] and Halvorsen and Smith [2], elasticities of demand for fuel consumption and carbon emissions can be calculated from the following:

$$
\frac{\partial \ln X_{i t}}{\partial \ln w_{j t}}=\left.\frac{\partial \ln X_{i t}}{\partial \ln w_{j t}}\right|_{\bar{N}, \bar{R}}+\frac{\partial \ln X_{i t}}{\partial \ln N_{t}^{*}} \frac{\partial \ln N_{t}^{*}}{\partial \ln w_{j t}}+\frac{\partial \ln X_{i t}}{\partial \ln R_{t}^{*}} \frac{\partial \ln R_{t}^{*}}{\partial \ln w_{j t}} \quad \forall i, j
$$

This equation illustrates that the complete demand response consists of three components, the first coming from direct substitution when carbon-free energy is held fixed and then from how factor prices affect the demand for carbon-free energy and how these demands affect carbon based energy. Solving the convexity conditions provides the demand equations for carbon-free energy. The second two expressions in Equation (5) are derived from the following convexity conditions for hydroelectric and nuclear energy and for renewable energy, respectively:

$$
\begin{aligned}
\frac{\partial G_{t}}{\partial N_{t}} & =\mu_{n t}^{*}=\frac{1}{2} \sum_{i=1}^{3} \delta_{n i} w_{i t}\left(\frac{Y_{t}}{N_{t}}\right)^{1 / 2}+\frac{1}{2} Y_{t}^{1 / 2} \sum_{i=1}^{3} w_{i t}\left[\gamma_{y n}\left(\frac{Y_{t}}{N_{t}}\right)^{1 / 2}+\gamma_{z n}\left(\frac{Z_{t}}{N_{t}}\right)^{1 / 2}\right] \\
& +\sum_{i=1}^{3} w_{i t}\left[\gamma_{n n}+\gamma_{n r}\left(\frac{R_{t}}{N_{t}}\right)^{1 / 2}\right] \\
\frac{\partial G_{t}}{\partial R_{t}} & =\mu_{r t}^{*}=\frac{1}{2} \sum_{i=1}^{3} \delta_{r i} w_{i t}\left(\frac{Y_{t}}{R_{t}}\right)^{1 / 2}+\frac{1}{2} Y_{t}^{1 / 2} \sum_{i=1}^{3} w_{i t}\left[\gamma_{y r}\left(\frac{Y_{t}}{R_{t}}\right)^{1 / 2}+\gamma_{z r}\left(\frac{Z_{t}}{R_{t}}\right)^{1 / 2}\right] \\
& +\sum_{i=1}^{3} w_{i t}\left[\gamma_{r r}+\gamma_{n r}\left(\frac{N_{t}}{R_{t}}\right)^{1 / 2}\right]
\end{aligned}
$$

where $\mu_{n t}^{*}$ and $\mu_{r t}^{*}$ are the shadow values for carbon-free energy resources. The equations show that the shadow values for carbon-free energy are equations of carbon prices. Solving Equations (7) and (8) for $N_{t}$ and $R_{t}$ and differentiating with respect to factor prices provides a solution for the second two terms in Equation (6) and for the elasticities of demand for carbon free energy resources. Likewise, the elasticities of demand for fossil fuels and carbon permits with respect to shadow values for carbon free energy are as follows: 


$$
\begin{aligned}
& \frac{\partial \ln X_{i t}}{\partial \ln \mu_{n t}}=\frac{\partial \ln X_{i t}}{\partial \ln N_{t}{ }^{*}} \frac{\partial \ln N_{t}^{*}}{\partial \ln \mu_{n t}}+\frac{\partial \ln X_{i t}}{\partial \ln R_{t}^{*}} \frac{\partial \ln R_{t}^{*}}{\partial \ln \mu_{n t}} \\
& \frac{\partial \ln X_{i t}}{\partial \ln \mu_{r t}}=\frac{\partial \ln X_{i t}}{\partial \ln N_{t}{ }^{*}} \frac{\partial \ln N_{t}^{*}}{\partial \ln \mu_{r t}}+\frac{\partial \ln X_{i t}}{\partial \ln R_{t}^{*}} \frac{\partial \ln R_{t}^{*}}{\partial \ln \mu_{r t}} \quad \forall i
\end{aligned}
$$

This approach of estimating a restricted cost equation allows the estimation of elasticities of demand for fossil fuel resources and carbon free energy when factor prices for the latter resources are unavailable. A complete derivation of the elasticities of demand, substitution, output, technical change, and marginal cost elasticities appears in an unpublished technical appendix available from the author upon request.

While the model can be estimated with full information maximum likelihood, a more robust procedure is estimation with Generalized Methods of Moments with country and monthly dummy variables and lagged values of the right-hand side variables, including those involving input prices, quasi-fixed factor levels, and output.

\section{An Overview of the Data Sample}

The above model is estimated with a pooled, monthly data sample across twelve countries in the EU from January 2002 to March 2008. The International Energy Agency (IEA) reports monthly electric power generation from fossil fuels, nuclear, hydroelectric, geothermal and renewable resources. The IEA does not report the types of combustible fuels but the EuroStat database does report the consumption of petroleum, coal, and natural gas in electric power generation. The EuoStat database, however, does not report data on generation from geothermal and renewable electricity generation. Given the rising importance of renewable energy in the generation portfolio, the more inclusive IEA data on generation is adopted in this study while the EuroStat data on fossil fuel use is utilized. A comparison of the generation data reported by the two agencies reveals the average differences are $3.2 \%$.

An overview of the generation and net imports data appears in Table 1, which reports the sample means. The largest producers of electricity are Germany, France, UK and Spain. The mid tier includes Sweden and Poland. The other six countries have total indigenous production between 3000 and $8000 \mathrm{GW}$ hours. All twelve countries in the sample produce fossil-fuel-fired electricity. Five countries do not produce nuclear electricity, including Austria, Denmark, Greece, Portugal, and Poland. Denmark and the Netherlands produce negligible amounts of hydroelectric power while France and Sweden are the largest producers of hydroelectricity. Germany and Spain produce rather substantial amounts of renewable electricity (see Table 1).

An overview of coal, petroleum, and natural gas consumption in electric power generation appears in Table 2. The largest coal consumers include Germany, UK, Poland, and Spain. UK is the largest consumer of natural gas, Germany is second, and the Netherlands and Spain are significant consumers as well. Spain consumes significant amounts of petroleum to generate power along with Greece, UK, and Germany. 
Table 1. Average annual electric power generation by type and net imports in gigawatt hours, January 2004 to March 2008.

\begin{tabular}{ccrcccrr}
\hline Country & Fossil Fuel & Nuclear & Hydroelectric & Renewable & $\begin{array}{c}\text { Indigenous } \\
\text { Production }\end{array}$ & $\begin{array}{c}\text { Net } \\
\text { Imports }\end{array}$ & Total \\
\hline Austria & 1,921 & 0 & 2,969 & 96 & 4,985 & 372 & 5,358 \\
Denmark & 2,732 & 0 & 2 & 529 & 3,263 & -246 & 3,017 \\
Finland & 3,479 & 1,837 & 1,041 & 14 & 6,371 & 739 & 7,109 \\
France & 4,856 & 35,470 & 5,164 & 176 & 45,666 & $-4,268$ & 41,398 \\
Germany & 30,428 & 12,734 & 2,207 & 2,255 & 47,624 & -694 & 46,930 \\
Greece & 4,061 & 0 & 400 & 105 & 4,566 & 251 & 4,817 \\
Netherlands & 7,454 & 311 & 8 & 185 & 7,958 & 1,249 & 9,207 \\
Portugal & 2,777 & 0 & 827 & 168 & 3,773 & 418 & 4,190 \\
Spain & 13,636 & 4,846 & 2,592 & 1,607 & 22,681 & -182 & 22,499 \\
Poland & 11,480 & 0 & 290 & 20 & 11,790 & -629 & 11,161 \\
Sweden & 1,075 & 5,645 & 5,315 & 82 & 12,117 & 112 & 12,229 \\
UK & 24,784 & 6,022 & 646 & 255 & 31,706 & 493 & 32,199 \\
\hline
\end{tabular}

Table 2. Average annual fossil fuel consumption in terajoules, January 2004 to March 2008.

\begin{tabular}{crrr}
\hline Country & \multicolumn{1}{c}{ Coal } & Petroleum & Natural Gas \\
\hline Austria & 4,348 & 529 & 6,096 \\
Denmark & 15,192 & 1,628 & 3,382 \\
Finland & 6,140 & 971 & 6,930 \\
France & 18,236 & 1,390 & 2,572 \\
Germany & 107,066 & 2,654 & 44,666 \\
Greece & 7 & 6,991 & 6,779 \\
Netherlands & 21,346 & 57 & 24,951 \\
Portugal & 11,041 & 2,625 & 5,813 \\
Spain & 57,891 & 13,329 & 25,930 \\
Poland & 77,898 & 8 & 3,103 \\
Sweden & 698 & 526 & 252 \\
UK & 102,979 & 4,510 & 100,373 \\
\hline
\end{tabular}

Trends in the carbon intensity of indigenous electricity production are displayed in Figure 1. Carbon emissions are computed by multiplying fuel use by its respective carbon emission factor. The denominator in Figure 1 is indigenous electricity production to reflect the shifts between combustible fuels and carbon-free generation such as nuclear, hydroelectric, and renewable energy resources. For the aggregate of the twelve countries, carbon intensity decreased from 2004 to 2005 but then increased very slightly from 2005 to 2007 . There is a great deal of variability in carbon intensity trends among countries. Poland has the highest carbon intensity among the twelve countries, which actually increased between 2005 and 2007. Portugal, Netherlands, Spain, Austria, and Finland reduced the carbon intensity of their electricity production. Electricity generation from renewable energy increased in each of these countries. Were it not for expanded use of renewable energy, Germany would have experienced even greater growth in the carbon intensity of their electricity production. France and 
Sweden have very low levels of carbon intensity due to their extensive use of nuclear and hydroelectric resources to generate electric power (see Figure 1 and Table 1).

Figure 1. Carbon intensity of indigenous electricity production by country, 2004 to 2007.

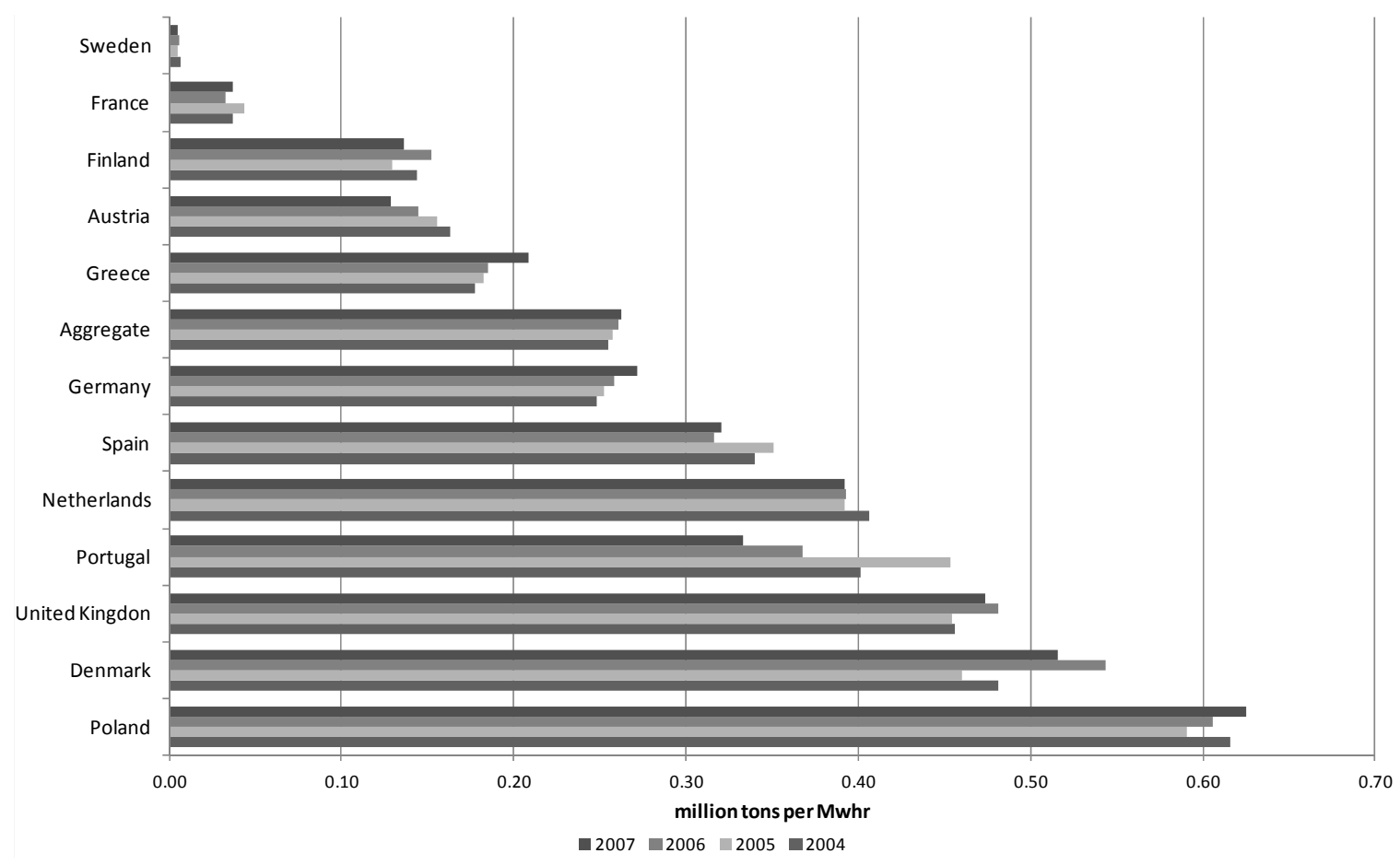

The shares of natural gas in total fossil fuel consumption by country for the four full calendar years 2004 to 2007 are displayed in Figure 2. The share of natural gas for the aggregate of the twelve countries increased from 33 to $36 \%$ from 2004 to 2007. Expanding use of gas in Greece, the Netherlands, the United Kingdom, Portugal, Spain, and Sweden offset declines in Finland and Denmark and the flat trends in the other countries. The empirical model below may shed some light on the role of relative fuel and carbon permit prices in these fuel share adjustments. Nevertheless, the shift to less carbon intensive natural gas, the increasing generation of renewable energy (see Figure 3), and the declining carbon intensity in several countries suggests that carbon dioxide emission abatement may have occurred even during the trial period for the EU ETS.

During the first phase of the EU ETS, exchanges emerged to trade spot and futures contracts derived from Phase I and Phase II. Because the Phase I allowances could not be carried over into Phase II, future contracts based either on Phase I or Phase II allowances were independently priced. For a variety of reasons, evidence suggests that allowances were over-issued during Phase I by about eighty million tons, or roughly $4 \%$ of the total EU cap (Ellerman and Buckner [21]). This became apparent to market participants with the release of 2005 emissions data in April 2006, at which point contract prices for first-phase allowances began a steep decline to near-zero levels (see Figure 4). Still, when allocations for the second phase were determined, additional oversight was given to the European Commission and this appears to have resulted in a binding Phase II cap. This seems to have maintained confidence in the system as a whole. Prices on the nearby second-phase December 2008 contract fell, but the contract retained most of its value and recovered with time (Figure 4). 
Figure 2. Shares of natural gas in fossil fuel use in power generation by country, 2004 to 2007.

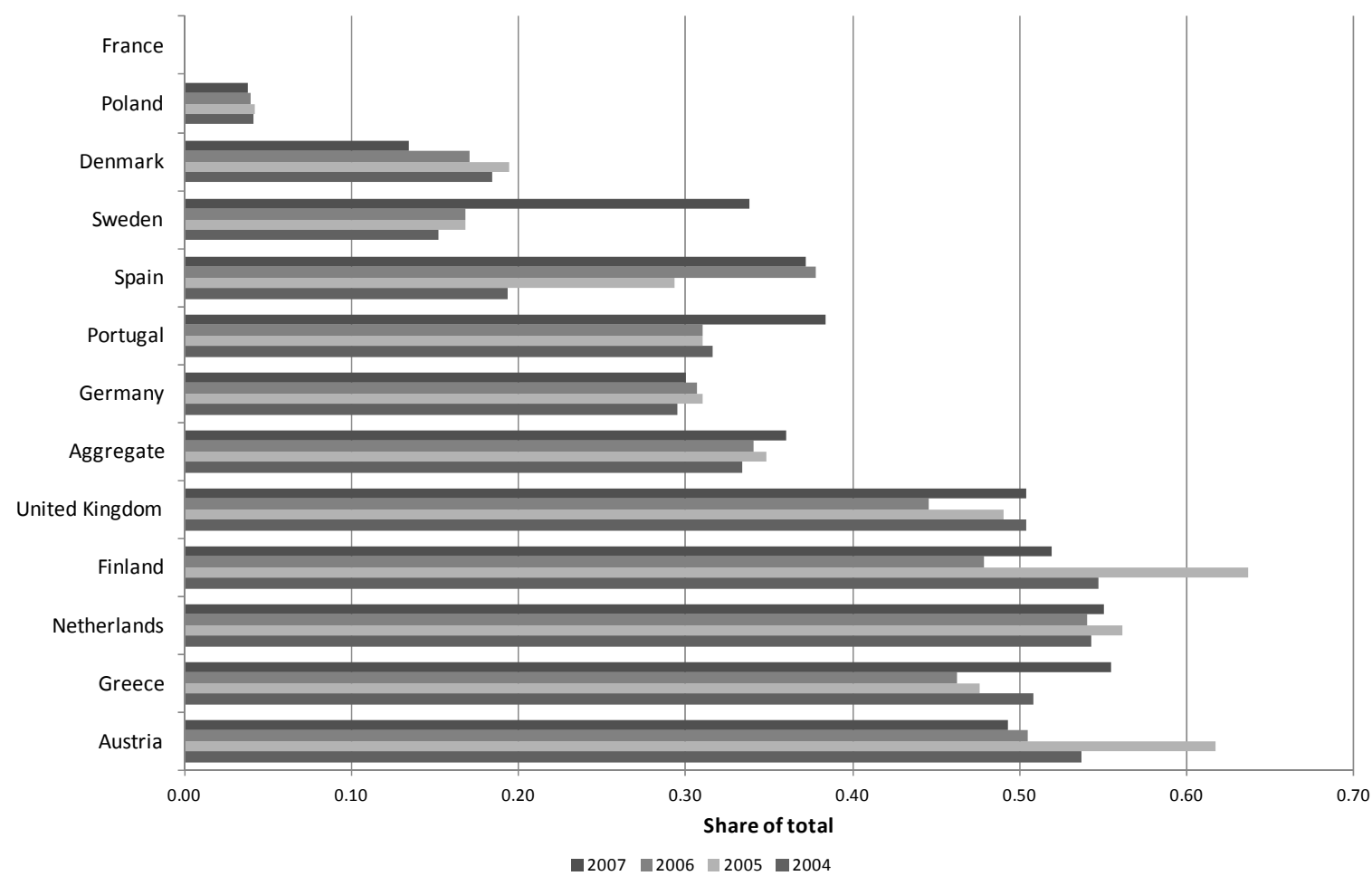

Figure 3. Renewable electricity generation, 2004-2007.

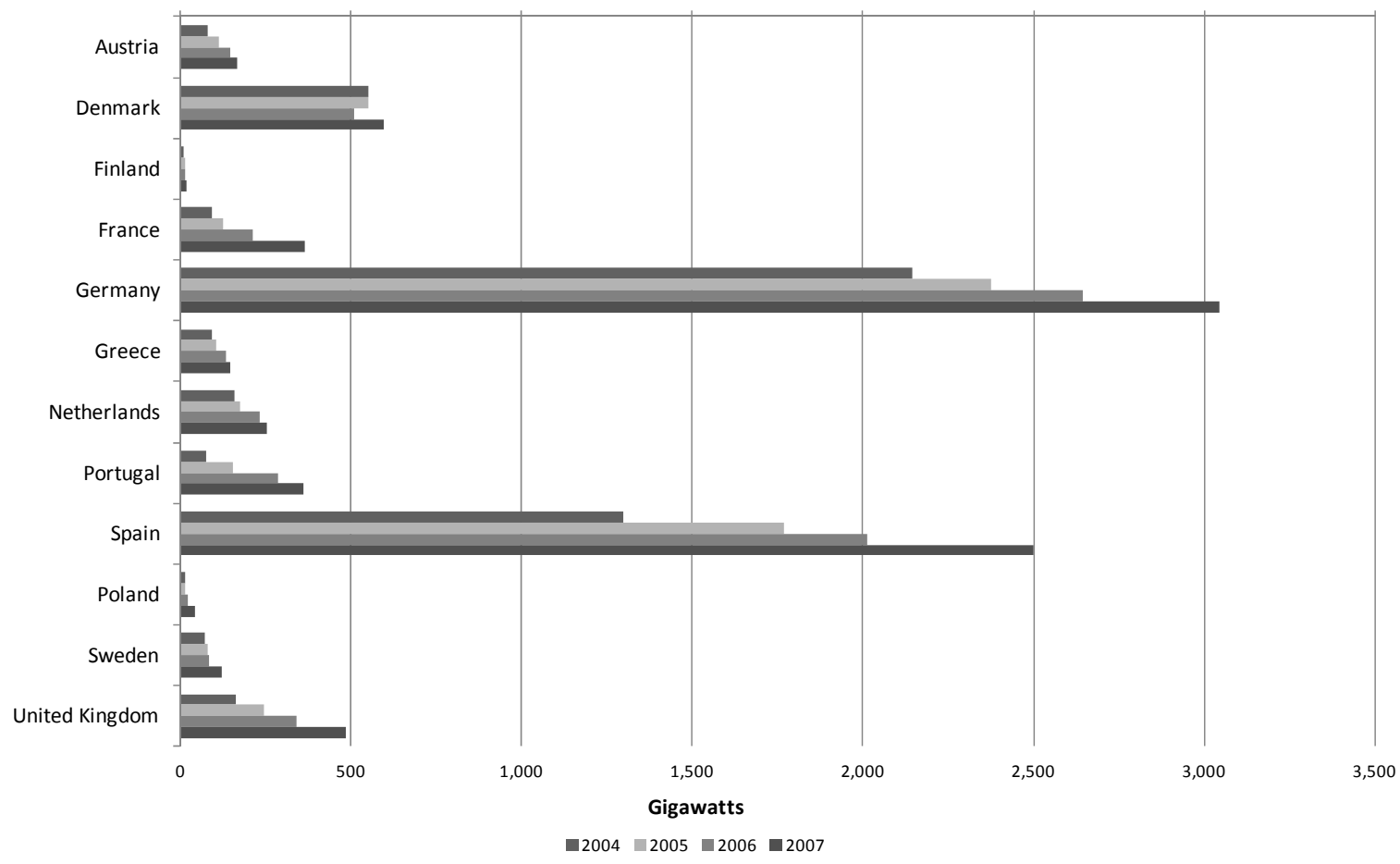

Although the over allocation of allowances shook markets, the sustained value of the December 2008 contract suggests that a system-wide structural break was avoided. We use spot prices, as reported by PointCarbon, rather than futures prices, since in the short-run, fuel substitution decisions are likely linked to the relative marginal costs of obtaining or selling marginal allowances. This reasonable proposition is tested in the analysis below by determining whether carbon prices are 
statistically significant in the input demand equations and we find that they are. Ironically, from a technical perspective, the added spread in the carbon price series stemming from the over allocation is helpful for the estimation procedure we employ.

Figure 4. EU ETS carbon emission allowance prices.

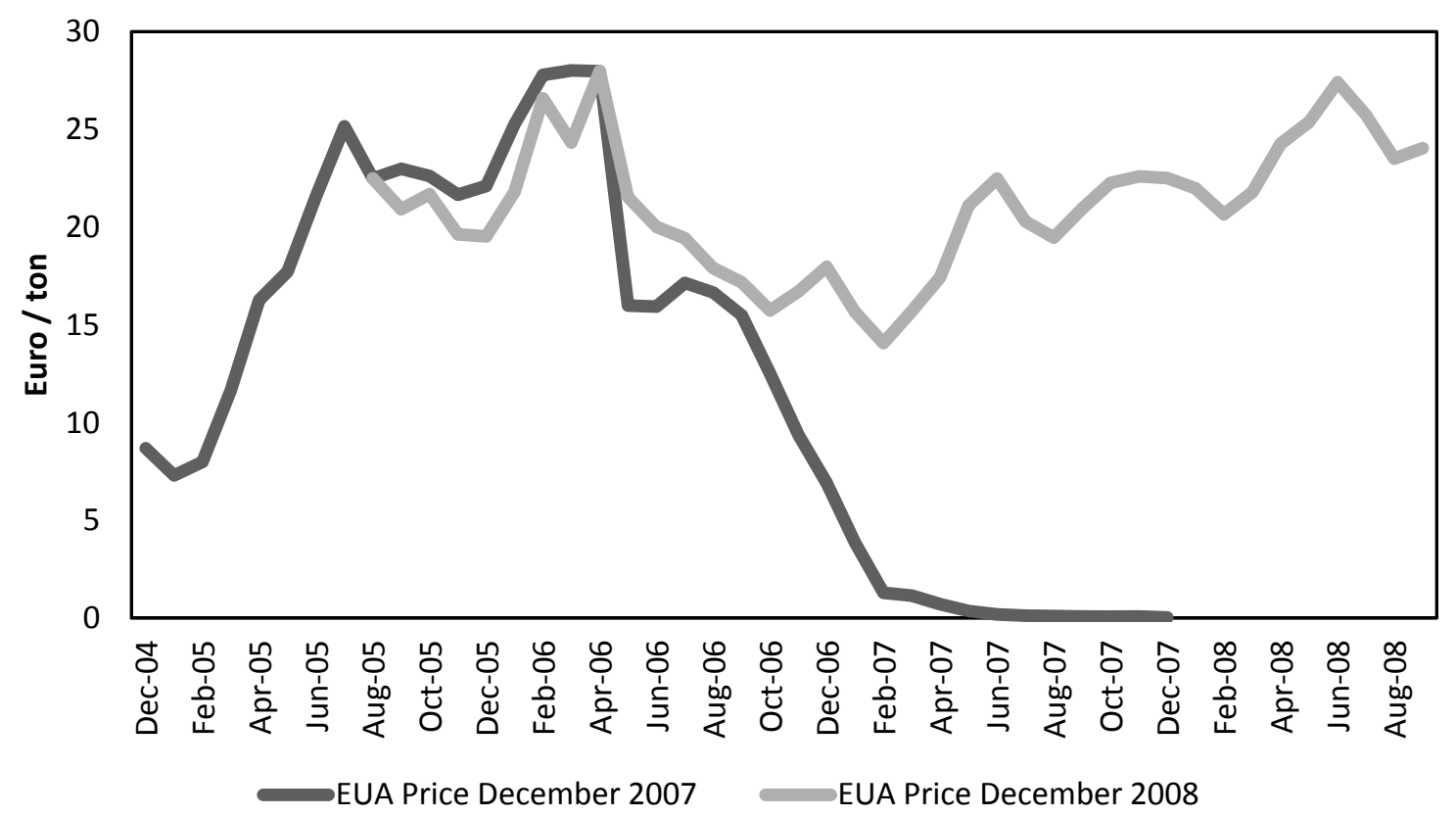

In interpreting our results, we should point out that the pricing incentives for short-run substitution in our model may be different from the incentives for new investment in capacity. Said somewhat differently, fuel-switching and related actions are short-term tactics meant to minimize costs, while investments are made in part with an expected flow of profits in mind. Ellerman [22], for one, argues that the investment decisions were guided by market valuations of traded Phase II allowances, based on prices for the December 2008 futures contract also shown in Figure 4. And while there is no clear reason to expect that such investments were brought forward into Phase I when spot prices were low, investment studies will need to reconcile the conflicting incentives given by the pricing of Phase I and Phase II allowances. As a check, we also estimated the model using the EU allowance futures price for the December 2007 contract reported from January through August 2005 and then the price on the December 2008 contract that began trading in August 2005 through March 2008 (see Figure 4). The econometric estimates are very similar.

Prices for natural gas, petroleum, and coal paid by electricity generators in the United Kingdom are directly observable on a monthly basis from UK [23]. For the other countries, this study estimates monthly prices based upon regional monthly wholesale prices published by Platts [24] for various market hubs in the EU and quarterly prices published by the International Energy Agency [25] that measure prices paid by end users including taxes. Quarterly averages are computed from the monthly data from Platts [24]. Next, we compute the ratio of these quarterly averages to the quarterly data reported by IEA [25]. These ratios represent the spreads between prices in each country and the market hub. Monthly estimates for prices in the remaining eleven countries result from multiplying these ratios by the monthly data from Platts. 


\section{Model Estimation Results}

The above econometric model of the restricted variable cost Equation (4) and the three variable input demand equations given by Equation (5) are estimated as a system of equations. While the data prior to January 2005 is displayed above for comparative purposes, this date marks the start of the sample for estimation. Given that fuel and carbon permit prices and output could be endogenous, an instrumental variables estimator is needed. The Generalized Method of Moments (GMM) estimator provides for consistent parameter estimates and allows correction of the standard errors for heteroscedasticity and autocorrelation in the error terms. The instruments include lagged values of input prices, generation levels for nuclear, hydroelectric, and renewable generation, total power generation, and country and monthly dummy variables. The lagged instruments vary for each equation and correspond with the specific specification of the right-hand side variables in Equations (4) and (5). So, for example, the instruments for the input demand equations include square roots of lagged price ratios. This approach is intended to ensure that the instruments are correlated with the explanatory variables but remain independent of the error terms. Country and monthly dummy variables are included as instruments in all four equations.

The test statistic of the over-identifying restrictions for the unrestricted model is 87.99 with a probability value of 0.655 , which suggests that the model given above cannot be rejected. Only one technological change coefficient was significant at the $5 \%$ level or less and that was for natural gas, which indicated gas-saving technological change, most likely reflecting the steady improvements in the thermal efficiency of combined cycle gas turbine technology. As a result, the hypothesis of non-neutral technological change is tested by computing a test statistic equal to the difference between the test statistics of the over-identifying restrictions for the unrestricted model and the restricted model with neutral technological change imposed via the following parameter restrictions: $\delta_{z i}=0 \forall i, \gamma_{y z}=\gamma_{z z}=\gamma_{z n}=\gamma_{z r}=0$. The value of this test statistic is 13.02 with a probability value of $7 \%$, indicating that the null hypothesis of neutral technological change cannot be rejected. This finding suggests that at least for the early stages of the EU ETS, exogenous technological change has not induced pervasive changes in the relative factor intensities of power generation. Moreover, the parameter estimates for the neutral technological change model are relatively close to those for the non-neutral model; there are no sign changes between the two sets of estimates.

As the discussion of the data reveals, several countries witnessed significant expansion of renewable energy. The key question is whether this expansion reflects changes in output and relative prices or other factors, represented by a time trend, such as technological change. For our sample with wide variation in generation technologies, cross-sectional effects are controlled by the use of country dummy variables. Following the tradition of neoclassical economics, changes in factor intensities apart from those associated with changes in relative prices and output are attributed to exogenous, non-neutral technological change. Non-neutral technical change is mostly embedded in the capital stock, which doesn't change in the short-run. We look for non-embedded non-neutral change and don't find much. That means that the adjustment process from high-carbon to low-carbon power generation takes time since it requires a rollover of capital.

As a result, the following presentation of results will focus on the estimates for the model assuming neutral technological change. In this case, the instruments involving the trend proxy for technological change are dropped and the model is re-estimated. The Sargan or Hansen's J-test of the over-identifying 
restrictions is 91.08 with 85 degrees of freedom and a probability value of $30.6 \%$. As expected, the model with neutral technological change cannot be rejected. The parameter estimates appear in Table 3 . Of the 36 country dummy variables, twenty have probability values that suggest they have a less than a $5 \%$ chance of being zero. For the twenty-one coefficients on the relative price, output, and quasi-fixed factors, twelve have probability values less than $5 \%$ and two less than $10 \%$.

Table 3. Generalized method of moments estimates.

\begin{tabular}{|c|c|c|c|c|c|c|c|}
\hline Parameter & Estimate & $t$-ratio & P-value & Parameter & Estimate & $t$-ratio & P-value \\
\hline$\delta_{1}^{1}$ & 0.192 & 1.6 & {$[0.112]$} & $\delta_{6}^{3}$ & -3.440 & -3.2 & {$[0.001]$} \\
\hline$\delta_{2}^{1}$ & -0.111 & -1.0 & {$[0.321]$} & $\delta_{7}^{3}$ & 3.726 & 2.1 & [0.039] \\
\hline$\delta_{3}^{1}$ & -0.288 & -1.8 & {$[0.071]$} & $\delta_{8}^{3}$ & -0.459 & -0.5 & {$[0.588]$} \\
\hline$\delta_{4}^{1}$ & 0.975 & 2.2 & [0.029] & $\delta_{9}^{3}$ & 1.966 & 0.6 & [0.542] \\
\hline$\delta_{5}^{1}$ & 0.212 & 0.5 & [0.609] & $\delta_{10}^{3}$ & -31.730 & -11.2 & {$[0.000]$} \\
\hline$\delta_{6}^{1}$ & -1.107 & -8.2 & {$[0.000]$} & $\delta_{11}^{3}$ & 1.996 & 1.0 & [0.341] \\
\hline$\delta_{7}^{1}$ & -0.968 & -4.6 & {$[0.000]$} & $\delta_{12}^{3}$ & 46.270 & 10.7 & {$[0.000]$} \\
\hline$\delta_{8}^{1}$ & 0.217 & 2.0 & {$[0.051]$} & $\alpha_{11}$ & 0.663 & 10.5 & {$[0.000]$} \\
\hline$\delta_{9}^{1}$ & 2.123 & 6.7 & {$[0.000]$} & $\alpha_{12}$ & -0.002 & -2.8 & {$[0.005]$} \\
\hline$\delta_{10}^{1}$ & 0.339 & 1.0 & [0.329] & $\alpha_{13}$ & 0.001 & 2.8 & {$[0.006]$} \\
\hline$\delta_{11}^{1}$ & 0.106 & 0.5 & {$[0.620]$} & $\alpha_{22}$ & 6.252 & 13.7 & {$[0.000]$} \\
\hline$\delta_{12}^{1}$ & 2.739 & 6.5 & {$[0.000]$} & $\alpha_{23}$ & 0.027 & 1.4 & [0.168] \\
\hline$\delta_{1}^{2}$ & -0.613 & -0.6 & {$[0.564]$} & $\alpha_{33}$ & 3.363 & 9.7 & {$[0.000]$} \\
\hline$\delta_{2}^{1}$ & 1.738 & 1.6 & {$[0.101]$} & $\delta_{y 1}$ & 0.021 & 1.7 & [0.097] \\
\hline$\delta_{3}^{2}$ & -5.601 & -3.6 & {$[0.000]$} & $\delta_{y 2}$ & 0.017 & 0.5 & {$[0.626]$} \\
\hline$\delta_{4}^{2}$ & 4.351 & 0.9 & {$[0.358]$} & $\delta_{y 3}$ & 0.021 & 0.7 & [0.482] \\
\hline$\delta_{5}^{2}$ & 11.360 & 2.5 & [0.011] & $\gamma_{y y}$ & -0.001 & -1.3 & {$[0.200]$} \\
\hline$\delta_{6}^{2}$ & -10.690 & -8.1 & {$[0.000]$} & $\delta_{n 1}$ & -0.712 & -14.8 & {$[0.000]$} \\
\hline$\delta_{7}^{2}$ & -15.010 & -6.4 & {$[0.000]$} & $\delta_{n 2}$ & -6.059 & -20.0 & {$[0.000]$} \\
\hline$\delta_{8}^{2}$ & 2.063 & 2.0 & {$[0.042]$} & $\delta_{n 3}$ & -3.751 & -14.1 & {$[0.000]$} \\
\hline$\delta_{9}^{2}$ & 24.470 & 7.0 & {$[0.000]$} & $\delta_{r 1}$ & -0.317 & -5.1 & {$[0.000]$} \\
\hline$\delta_{10}^{2}$ & 18.210 & 4.4 & {$[0.000]$} & $\delta_{r 2}$ & -4.097 & -8.0 & {$[0.000]$} \\
\hline$\delta_{11}^{2}$ & -1.651 & -0.8 & {$[0.426]$} & $\delta_{r 3}$ & 0.025 & 0.1 & [0.947] \\
\hline$\delta_{12}^{2}$ & 3.993 & 0.7 & [0.488] & $\gamma_{y n}$ & -0.004 & -1.9 & {$[0.056]$} \\
\hline$\delta_{1}^{3}$ & 3.310 & 3.1 & {$[0.002]$} & $\gamma_{y r}$ & -0.019 & -3.0 & [0.003] \\
\hline$\delta_{2}^{3}$ & -7.143 & -8.1 & {$[0.000]$} & $\gamma_{n n}$ & -0.012 & -0.4 & [0.653] \\
\hline$\delta_{3}^{3}$ & 1.409 & 1.2 & {$[0.250]$} & $\gamma_{n r}$ & 0.057 & 2.1 & {$[0.036]$} \\
\hline$\delta_{4}^{3}$ & 9.258 & 2.1 & [0.038] & $\gamma_{r r}$ & 0.024 & 0.4 & {$[0.708]$} \\
\hline$\delta_{5}^{3}$ & -16.460 & -3.8 & {$[0.000]$} & & & & \\
\hline
\end{tabular}


Table 4 reports the goodness of fit statistics, indicating an excellent fit of the data with R-squared coefficients ranging from 0.97 to 0.99 . The Durbin-Watson statistics indicate first-order autocorrelation, which is why we allow a first order moving average correction in the GMM estimation. An explicit structural correction for autocorrelation is not pursued because it could introduce specification error and would violate the conditions that allow the input demand equations to be integrated back to the cost equation. Given the relatively large sample size used in this study, the theoretical result that the GMM estimates are asymptotically efficient seems reasonable.

Table 4. Summary fit statistics.

\begin{tabular}{ccccc}
\hline Equation & $\begin{array}{c}\text { Mean of } \\
\text { Dependent Variable }\end{array}$ & $\begin{array}{c}\text { Standard Error } \\
\text { of Regression }\end{array}$ & R-Squared & Durbin-Watson \\
\hline Variable Cost & 293.4 & 30.18 & 0.9933 & 0.7104 \\
Carbon Permits & 4.512 & 0.5264 & 0.9891 & 0.6263 \\
High Carbon Fuels & 38.38 & 7.332 & 0.9701 & 0.6022 \\
Low Carbon Fuels & 21.28 & 5.089 & 0.9701 & 0.5723 \\
\hline
\end{tabular}

The elasticities of demand result from solving the envelope conditions for the quasi-fixed factors and differentiating these equations to obtain the elasticities. Given the use on monthly data, the elasticities are averages of hourly and daily decisions. This temporal aggregation is consistent with all previous studies of fuel substitution in electric utilities.

The estimated elasticities of demand appear in Table 5, where the diagonal elements are the own price elasticities, the off-diagonal are the cross-price elasticities, and that the final row and final column are cost and output elasticities. These elasticities are not necessarily equal because, as laid out in Equations (6) and (9), they contain the induced changes in quasi-fixed input levels from changes in prices for fuels, carbon emission permits, and output levels. Overall, they reflect inelastic factor demands. The demand for carbon permits is the most price inelastic of the five factors with an own price elasticity of -0.051 indicating that, ceteris paribus, a $10 \%$ increase in carbon permit prices results in $0.51 \%$ reduction in carbon emissions. The own price elasticities of oil and coal and natural gas are -0.210 and -0.116 , respectively. The own price elasticity of renewable energy, however, is considerably larger in absolute terms with an estimate of -0.743 reflecting significant substitution with carbon emissions and the carbon intensive aggregate of coal and oil generation. Renewable energy mandates and subsidies may account for these relatively larger substitution elasticities. Moreover, electricity from renewable energy sources, such as wind, are often used when available, which is another reason why considering these factors as quasi-fixed in the cost equation may be appropriate in this application.

The cross-price elasticity between natural gas and renewable energy is of particular interest because the intermittent nature of renewable energy requires some form of back-up power, which would imply a complementary relationship between these two inputs. Indeed, the results provide some evidence supporting this hypothesis with negative cross price elasticities between renewable energy and natural gas, although these elasticities are not statistically significant (see Table 5). Nevertheless, renewable energy is a significant substitute with carbon permits. The cross price elasticity between renewable energy and carbon permit demand suggests a $10 \%$ increase in the price of carbon permits induces a 1.6 increase in the demand for renewable energy. 
While some may view renewable generation capacity as "must-run," another view is that they run when they are available. Hence, their availability affects the utilization of other generation resources. This is consistent with our treatment of renewable as quasi-fixed, since power generated by renewable energy displaces carbon-based electricity. If, alternatively, factors such as "must-run" are important, then corresponding types of non-neutral change in the underlying cost equation would be significant; however, our results indicate that they are absent.

The output elasticities are all positive as expected with the natural gas output elasticity at 2.447 , reflecting the well-known role of natural gas generation as a peak fuel in supplying peaks and troughs in seasonal demand. The output elasticity of carbon permits is also significant at 1.991, suggesting that demand side reductions, if they can be achieved, would substantially reduce the demand for carbon emissions.

Table 5. Elasticities of demand and marginal cost (asymptotic $t$-ratios in parentheses).

\begin{tabular}{cccccccc}
\hline \multirow{2}{*}{ Factor/Cost } & \multicolumn{3}{c}{ Factor Prices } & & \multicolumn{2}{c}{ Shadow Values } & \multirow{2}{*}{ Output } \\
\cline { 2 - 4 } & Carbon & Coal \& Oil & Natural Gas & & Renewable & Nuclear & \\
\hline Carbon & -0.051 & -0.158 & -0.077 & & 0.101 & 0.185 & 1.991 \\
& $(5.4)$ & $(6.1)$ & $(5.0)$ & & $(3.3)$ & $(13.4)$ & $(28.0)$ \\
\hline Coal \& Oil & -0.065 & -0.210 & -0.071 & & 0.159 & 0.187 & 2.019 \\
& $(4.7)$ & $(5.2)$ & $(3.4)$ & & $(3.5)$ & $(12.3)$ & $(21.0)$ \\
\hline Natural Gas & -0.036 & -0.089 & -0.116 & & -0.003 & 0.244 & 2.447 \\
& $(4.3)$ & $(3.3)$ & $(6.6)$ & & $(0.1)$ & $(9.2)$ & $(16.7)$ \\
\hline Renewable & 0.161 & 0.564 & 0.001 & & -0.743 & 0.017 & 0.401 \\
& $(3.6)$ & $(5.1)$ & $(0.0)$ & & $(4.4)$ & $(1.8)$ & $(4.6)$ \\
\hline Nuclear & 0.027 & 0.075 & 0.074 & & 0.001 & -0.178 & 0.090 \\
& $(10.8)$ & $(15.6)$ & $(11.1)$ & & $(1.8)$ & $(16.7)$ & $(17.6)$ \\
\hline Marginal Cost & 0.140 & 0.382 & 0.341 & & 0.041 & 0.021 & 0.234 \\
& $(27.7)$ & $(21.3)$ & $(16.0)$ & & $(11.6)$ & $(3.1)$ & $(12.1)$ \\
\hline
\end{tabular}

The marginal cost elasticities are also all significant. The estimated carbon price elasticity of marginal cost is 0.14 (see Table 5), indicating that for every $10 \%$ increase in carbon prices, the marginal generation cost of electricity increases by $1.4 \%$. In comparison, the elasticity of short-run marginal cost with respect to coal and oil prices is 0.382 and the same elasticity with respect to natural gas prices is 0.341 (see Table 5). A markup pricing model was also estimated in which two additional estimating equations were added to Equations (4) and (5), a demand for electricity and a price markup over marginal cost equation derived by assuming electric utilities are engaged in monopoly pricing. The estimated price elasticities of demand holding output fixed are very similar to the results presented above. The elasticities in this context, which allows for endogenous output and prices, are very complicated and at this juncture of this research would obscure our focus on technological change and substitution. Nevertheless, this approach may merit future investigation.

The last set of elasticities is the Morishima elasticities of substitution, which are a unit-less measure of substitution. The analysis by Blackorby and Russell [25] proves that the Morishima elasticity is a superior measure of substitution for this study because it provides a clear distinction between 
substitutions induced by carbon permit prices versus other input price changes. Morishima elasticities are defined as follows:

$$
M_{i j}=\frac{\partial \ln x_{j}}{\partial \ln w_{i}}-\frac{\partial \ln x_{i}}{\partial \ln w_{i}}=\frac{-\partial \ln \left(x_{i} / x_{j}\right)}{\partial \ln w_{i}}
$$

These elasticities measure the curvature of an isoquant, or the percentage change in a factor input ratio for a given percentage change in price, holding all other factor prices constant. As the above equation illustrates, the effect of varying $w_{i}$ on the factor input ratio, $x_{i} / x_{j}$, is composed of two parts - the effect of $w_{i}$ on $x_{i}$ and the effect of $w_{i}$ on $x_{j}$. Blackorby and Russell [26] show that these elasticities are inherently asymmetric.

The estimated Morishima elasticities of substitution appear in Table 6. These estimates provide a basis for comparing the degree of substitutability or complementarity between pairs of factors of production. All but two of these 20 substitution elasticities are significant at the five percent level. Only one significant complementarity was found between the coal and oil aggregate and carbon emissions. Of the remaining 19 elasticities, 17 indicate significant substitution. The largest substitution elasticities involve renewable energy. For instance, the ratio of renewable energy to carbon emissions rises $0.843 \%$ for every percent increase in carbon emission prices. In contrast, the ratio of nuclear energy to carbon emissions increases $0.362 \%$ for each percent change in carbon emission prices. Similarly, the ratio of natural gas to carbon emissions rises only $0.039 \%$ for every percent change in carbon emission prices. These results suggest that electricity producers achieved reductions in carbon emissions by increasing their utilization of renewable resources and nuclear energy. Renewable energy is a significant substitute for coal and oil in power generation with a $10 \%$ reduction in renewable energy prices inducing an estimated $2.11 \%$ reduction in the ratio of coal and oil use to renewable energy use. Nuclear energy is also a significant substitute with carbon emissions and with all fuels, even renewable energy.

Table 6. Morishima elasticities of substitution (asymptotic $t$-ratios in parentheses).

\begin{tabular}{ccccccc}
\hline \multirow{2}{*}{ Input } & \multicolumn{3}{c}{ Factor Prices } & & \multicolumn{2}{c}{ Shadow Values } \\
\cline { 2 - 4 } \cline { 7 - 7 } & Carbon & Coal \& Oil & Natural Gas & & Renewable & Nuclear \\
\hline Carbon & & -0.014 & 0.014 & & 0.211 & 0.078 \\
& & $(2.8)$ & $(1.2)$ & & $(4.0)$ & $(7.0)$ \\
\hline Coal \& Oil & 0.052 & & 0.121 & & 0.211 & 0.078 \\
& $(2.9)$ & & $(2.1)$ & & $(4.0)$ & $(7.0)$ \\
\hline Natural Gas & 0.039 & 0.045 & & & 0.117 & 0.190 \\
& $(3.2)$ & $(2.3)$ & & & $(1.3)$ & $(8.1)$ \\
\hline Renewable & 0.843 & 0.901 & 0.739 & & 0.744 \\
& $(4.3)$ & $(4.3)$ & $(4.1)$ & & $(4.4)$ \\
\hline Nuclear & 0.362 & 0.364 & 0.422 & & 0.195 & \\
& $(15.2)$ & $(15.0)$ & $(11.8)$ & & $(11.3)$ & \\
\hline
\end{tabular}

Despite the over-allocation of permits and other problems during the early phases of the European Union's Emission Trading System, the econometric evidence presented above suggests statistically 
significant price-induced technology switching or substitution between carbon free energy and fossil fuels in the production of electricity in the short-run.

\section{Conclusions}

This study provides an analysis of the underlying economic forces inducing adjustments in the mix of technologies used in the electric power industry during the first phase of the European Unions Emissions Trading System regulating emissions of greenhouse gas emissions. Our empirical analysis examines the demand for carbon permits, carbon based fuels, and carbon-free energy for 12 European countries using monthly data on fuels use, prices, and electricity generation. The model is unique because it considers all possible sources of generation within one model. Heretofore, empirical models of factor substitution in electric power generation were confined to studies of steam power generation using combustible fuels, neglecting nuclear, hydroelectric, and renewable energy resources. This study uses a restricted variable cost equation to impute substitution with carbon based and carbon free energy.

Despite low emission permit prices, this paper finds statistically significant substitution between fossil fuels and carbon free sources of energy for electric power production. The largest substitution possibilities involved renewable energy resources. As discussed, renewables generate both power and potential revenue streams from the sale of freed-up allowances. As a consequence, new investments have been brought on line. High carbon prices give added incentives to extract the most when weather conditions allow, including speeding repairs and maintenance cycles. Significant substitution between fossil fuels and nuclear energy also was found. Overall, the results suggest that electricity power producers reduced their carbon dioxide emissions by switching to renewable and nuclear power. The natural gas substitution elasticities with respect to carbon permit prices, coal and oil prices, and nuclear shadow values also are significant but relatively smaller in magnitude than the elasticities of substitution between carbon-based energy and renewable and nuclear energy resources. So despite the over-allocation of carbon emission permits, these findings suggest that the EU ETS encouraged price-induced substitution between fossil fuels and carbon free energy in the short-run. This study affirms a time-tested proposition by economists that prices do matter and, in this case, even in the early stages on the EU ETS market.

\section{Acknowledgments}

Research assistance from Muhammed Hassan is gratefully acknowledged. The authors also thank the World Bank's Knowledge for Change program and the School of Energy Resources at the University of Wyoming for supporting this research. Comments and suggestions from brown bag participants from the Economics and Finance Department at the University of Wyoming are appreciated. We would also like to thank two anonymous reviewers for their constructive comments. Any errors or omissions are the responsibility of the authors.

\section{References}

1. Ellerman, A.D.; Buchner, B.; Carraro, C. Allocation in the European Emissions Trading Scheme: Rights, Rents, and Fairness; Cambridge University Press: New York, NY, USA, 2007. 
2. Halvorsen, R.; Smith, T.R. Substitution Possibilities for unpriced natural resources: Restricted cost functions for the Canadian metal mining industry. Rev. Econ. Stat. 1986, 68, 398-405.

3. Nerlove, M. Returns to scale in electricity supply. In Measurement in Economics: Studies in Mathematical Economics and Econometrics in Memory of Yehuda Grunfeld; Christ, C., Ed.; Stanford University Press: Chicago, IL, USA, 1963; pp. 167-198.

4. Christensen, L.; Greene, W. Economies of scale in U.S. electric power generation. J. Polit. Econ. 1976, 84, 655-676.

5. Atkinson, S.; Halvorsen, R. Interfuel substitution in steam electric power generation. J. Polit. Econ. 1976, 84, 959-978.

6. Cowing, T.; Smith, V. The estimation of production technology: A survey of econometric analyses of steam-electric generation. Land Econ. 1978, 54, 156-186.

7. Hobbs, B. Optimization methods for electric utility resource planning. Eur. J. Oper. Res. 1995, 83, 1-20.

8. De Leyva, E.; Lekander, P. Climate change for Europe's utilities. McKinsey Q. 2003, 1, 120-131.

9. Delarue, E.; D'haeseleer, W. Price determination of ETS allowances through the switching level of coal and gas in the power sector. Energy Res. 2007, 31, 1001-1015.

10. Bird, L.; Bolinger, M.; Gagliano, T.; Wiser, R.; Brown, M.; Parsons, B. Policies and market factors driving wind power development in the United States. Energy Policy 2005, 33, 1397-1407.

11. Hoffmann, V. EUETS and investment decisions: The case of the German electricity industry. Eur. Manag. J. 2007, 25, 464-474.

12. Butler, L.; Neuhoff, K. Comparison of feed-in tariff, quota and auction mechanisms to support wind power development. Renew. Energy 2008, 33, 1854-1867.

13. Nicolosi, M. Wind power integration and power system flexibility-An empirical analysis of extreme events in Germany under the new negative price regime. Energy Policy 2010, 38, 7257-7268.

14. Watanabe, R.; Robinson, G. The European Union Emissions Trading Scheme (EU ETS). Clim. Policy 2005, 5, 10-14.

15. Convery, F.J.; Redmond, L. Market and price developments in the European Union Emissions Trading Scheme. Rev. Environ. Econ. Policy 2007, 1, 88-111.

16. Europa, Emissions Trading Scheme (EU ETS). Available online: http://ec.europa.eu/clima/ policies/ets/index_en.htm (accessed on 17 October 2012).

17. Larson, D.; Ambrosi, P.; Dinar, A.; Rhamn, R.; Entler, R. A review of carbon market policies and research. Int. Rev. Environ. Resour. Econ. 2008, 2, 177-236.

18. Considine, T.; Larson, D. The environment as a factor of production. J. Environ. Econ. Manag. 2006, 52, 645-62.

19. Morrison, C. Quasi-fixed inputs in U.S. and Japanese manufacturing: A generalized leontief restricted cost function approach. Rev. Econ. Stat. 1988, 70, 275-287.

20. Caves, D.; Christensen, L. Global properties of flexible functional forms. Am. Econ. Rev. 1980, 70, 422-432.

21. Ellerman, A.; Buchner, B. The European Union Emissions Trading Scheme: Origins, allocation, and early results. Rev. Environ. Econ. Policy 2007, 1, 66-87. 
22. Ellerman, A. The EU Emission Trading Scheme: Prototype of A Global System? The Harvard Project on International Climate Agreements; Kennedy School of Government, Harvard University: Cambridge, MA, USA, 2008; Discussion Paper 08-02.

23. Energy Price Statistics. United Kingdom Department of Energy and Climate Change: London, UK, 2012. Available online: http://www.decc.gov.uk/en/content/cms/statistics/energy_stats/ prices/prices.aspx (accessed on 17 October 2012).

24. Platts Energy Service. Custom Energy Market Data, 2012. Available online: http://www.platts.com/Products/marketdataelectricpower (accessed on 17 October 2012).

25. International Energy Agency. Energy, Prices, and Taxes, 2009 ed.; International Energy Agency: Paris, France, 2009.

26. Blackorby, C.; Russell, R. Will the real elasticity of substitution please stand up? Am. Econ. Rev. 1989, 79, 882-888.

(C) 2012 by the authors; licensee MDPI, Basel, Switzerland. This article is an open access article distributed under the terms and conditions of the Creative Commons Attribution license (http://creativecommons.org/licenses/by/3.0/). 